\title{
Modeling and Optimization of Carbon Dioxide Removal in Packed Bed Column Reactor
}

\author{
K. Thirugnanasambandham \\ State University of Maringá, Department of Chemical Engineering, Av. Colombo, Maringá-PR, Brazil \\ E-Mail: thirusambath5@gmail.com
}

\begin{abstract}
Global warming due to greenhouse gases has become a serious global issue. Extensive efforts are being made to fighting this phenomenon through carbon capture as carbon dioxide $\left(\mathrm{CO}_{2}\right)$ is its major contributor. This study focused on $\mathrm{CO}_{2}$ capture in packed bed column reactor using Poly-(D) glucosamine under the various process parameters such as temperature, feed flow rate and mass of the adsorbent. Statistical design of experiments was carried out in order to analysis the effect process parameters on the capacity of $\mathrm{CO}_{2}$ capture in packed bed column. The obtained results show that feed flow rate has the significant affect compared to others. The maximum of $956 \mathrm{mg}$ of $\mathrm{CO}_{2}$ is captured under the following operating conditions; temperature of $40^{\circ} \mathrm{C}$, feed flow rate of $30 \mathrm{ml} / \mathrm{min}$ and $0.25 \mathrm{~g}$ of the Poly-(D) glucosamine. The ability of Poly-(D) glucosamine to capture the $\mathrm{CO}_{2}$ in packed bed column is confirmed.
\end{abstract}

Keywords: $\mathrm{CO}_{2}$ Capture, Packed Bed Column, Poly-(D) Glucosamine, Adsorption, Optimization

\section{INTRODUCTION}

Nowadays, fossil fuels are the key conventional energy source and consumption of them will increase constantly, every day [1]. The combustion of very huge amount of fossil fuels releases, carbon dioxide and other greenhouse gases that have a significant impact on global warming and climate change. The global warming and greenhouse effect have become serious global environmental issues [2]. The content of carbon dioxide in the atmosphere has increased from $2.84 \times 10^{-4}$ before the industrial revolution to $3.56 \times$ $10^{-4}$. Hence, the stability, safety and environment acceptability of $\mathrm{CO}_{2}$ capture methods have been paid worldwide notice. Therefore, there is critical need to develop a technology, which reduces the carbon dioxide in atmosphere [3].

The technologies include the chemical absorption and adsorption methods, membrane separation and chemical looping combustion, underground storage technology, terrestrial vegetation and marine microalgae fixation were used for $\mathrm{CO}_{2}$ capture. Among these technologies, adsorption is the most favorable technique because of its advantages such as high adsorption capacity, low cost and easy to operate [4]. Moreover, the key desired characteristics of the adsorbent in adsorption is high density (it allows operation at higher velocity, so smaller adsorber vessels are needed for carrying out preferred level of separation), a wide particle size allocation and high porosity (reduced mass transfer resistances and resulting in enhanced dynamic adsorption capacity. Packed beds reactors are mainly used for $\mathrm{CO}_{2}$ capture using various adsorbents [5]. The advantage of using a packed bed reactor is the higher conversion per weight of catalyst than other catalytic reactors [6]. The conversion is based on the amount of the solid catalyst rather than the volume of the reactor. Many researchers have reported the impact of parameters (temperature, feed flow rate and mass of the adsorbent) on the performance of packed beds, with different adsorbents and columns. Moreover, optimization of theses parameters will improve the adsorption performance [7-9].

Best of our knowledge, none of studies were reported for the $\mathrm{CO}_{2}$ capture in packed bed column via statistical methods. Response surface methodology (RSM) coupled with Box-Behnken design (BBD) is a statistical method which used to analyze the influence of effect process parameters in various process [10]. Hence, in this study an attempt has been made to study the individual and interactive effect of process parameters such as temperature, feed flow rate and mass of the adsorbent on $\mathrm{CO}_{2}$ capture in packed bed column. Also the response surface methodology coupled with numerical optimization was applied to model and optimize the $\mathrm{CO}_{2}$ capture process in packed bed column. It is believed that, the results obtained from this study will be useful understand the relationship between the process parameters and $\mathrm{CO}_{2}$ capture, mathematically.

\section{MATERIALS AND METHODS}

\section{A. Chemicals and Experimental Setup}

The entire chemical used in this study is analytical grade and purchased from local suppliers. The experimental set up used in this study was reported in elsewhere (Muofhe et al., 2017) with slight modifications. The performance evaluation of Poly-(D) glucosamine was determined using a gas mixture containing $\mathrm{CO}_{2}(15 \%)$ and $\mathrm{N}_{2}$ (85\%).

\section{B. Modeling}

Response surface methodology (RSM) coupled with BoxBehnken design (BBD) was used to analyze the influence of effect process parameters on $\mathrm{CO}_{2}$ capture in packed bed column. Experimental runs were established based on a $\mathrm{BBD}$ and the complete design consists of 17 experiments were designed and the obtained data was analyzed by 
multiple regression analysis [11]. Then, the individual and interactive effects of process variables on $\mathrm{CO}_{2}$ capture in packed bed column were determined by constructing response surface plots. Finally, optimization of process variables for maximum $\mathrm{CO}_{2}$ capture was carried out by numerical optimization technique [12]. All the statistical analyses were carried out with Stat ease Design Expert 8.0.7.1.

\section{RESULTS AND DISCUSSION}

\section{A. Effect of Temperature}

Temperature is one of the key process variables for the packed bed column performance on $\mathrm{CO}_{2}$ capture. To examine effect of temperature on $\mathrm{CO}_{2}$ capture experiments were carried out in temperature $\left(25-75^{\circ} \mathrm{C}\right)$ and the results are shown in Fig. 1.

From the observations, it is found that, the $\mathrm{CO}_{2}$ capture is increased rapidly with increasing the temperature upto $60^{\circ} \mathrm{C}$. This phenomenon could be explained by that, the increase in temperature increases the adsorption capacity Poly-(D) glucosamine, which improves the $\mathrm{CO}_{2}$ capture.

Beyond, temperature of $60^{\circ} \mathrm{C}$ shows the negligible effect on $\mathrm{CO}_{2}$ capture. Similar observations were obtained for carbon dioxide adsorption hysteresis in ultramicroporous metalorganic frameworks (MOFs) [13].
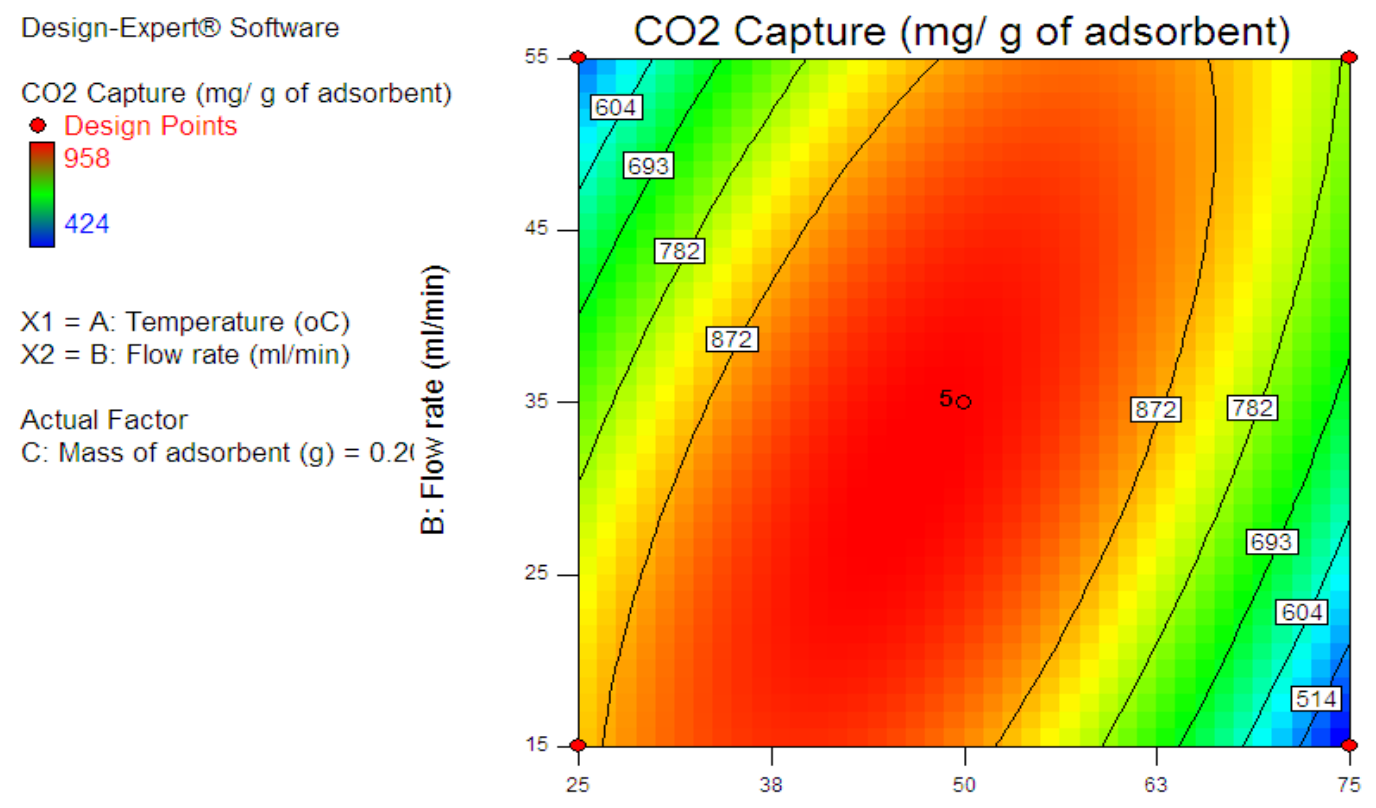

A: Temperature $(\mathrm{OC})$
Fig. 1 Response surface plots representing the effect of process variables on $\mathrm{CO}_{2}$ capture (A and B)

\section{B. Effect of Flow Rate}

Flow rate is one of the most important parameter that affects the $\mathrm{CO}_{2}$ capture in packed bed column, significantly. In order to study the effect of flow rate on $\mathrm{CO}_{2}$ capture in packed bed column, experiments were carried out in various flow rates (15-55 ml/min) and results are depicted in Fig. 2.

From the results, it is found that $\mathrm{CO}_{2}$ capture in packed bed column is increased with increasing flow rate upto 45 $\mathrm{ml} / \mathrm{min}$. This may be due to the fact that more mixture would be spread on the packing surface, and this leads to an increase in the interfacial area per unit volume and hence $\mathrm{CO}_{2}$ capture in packed bed column is increased. Thereafter, there is a negligible effect on the $\mathrm{CO}_{2}$ capture. Similar kind of results was obtained for $\mathrm{CO}_{2}$ adsorption from ambient air using a supported amine based sorbent in a fixed bed reactor [14].

\section{Effect of Mass of Adsorbent}

Mass of the adsorbent used in $\mathrm{CO}_{2}$ capture in packed bed column significally affects the process performance. Because the surface of adsorbent is the main factor to adsorption and it is directly proportional to mass. Hence, various adsorbent mass (0.1-0.3 g) are employed in order to determine its effect on $\mathrm{CO}_{2}$ capture in packed bed column.

From the results (Fig. 3), it was observed that, the maximum $\mathrm{CO}_{2}$ capture in packed bed column is obtained in $0.25 \mathrm{~g}$. This can explain by the fact that, reactive sites are directly proportional to mass. Hence, $\mathrm{CO}_{2}$ capture is increased with increasing mass of adsorbent. The trend obtained this study is close agreement with $\mathrm{CO}_{2}$ adsorbent developed with high adsorption properties in a coal mine refuge chamber [15]. 
Design-Expert(B) Software

CO2 Capture (mg/ g of adsorbent)

- Design Points

958

424

$\mathrm{X} 1=\mathrm{B}:$ Flow rate $(\mathrm{ml} / \mathrm{min})$

$\mathrm{X} 2=\mathrm{C}$ : Mass of adsorbent $(\mathrm{g})$

Actual Factor

A: Temperature $(\mathrm{OC})=50$

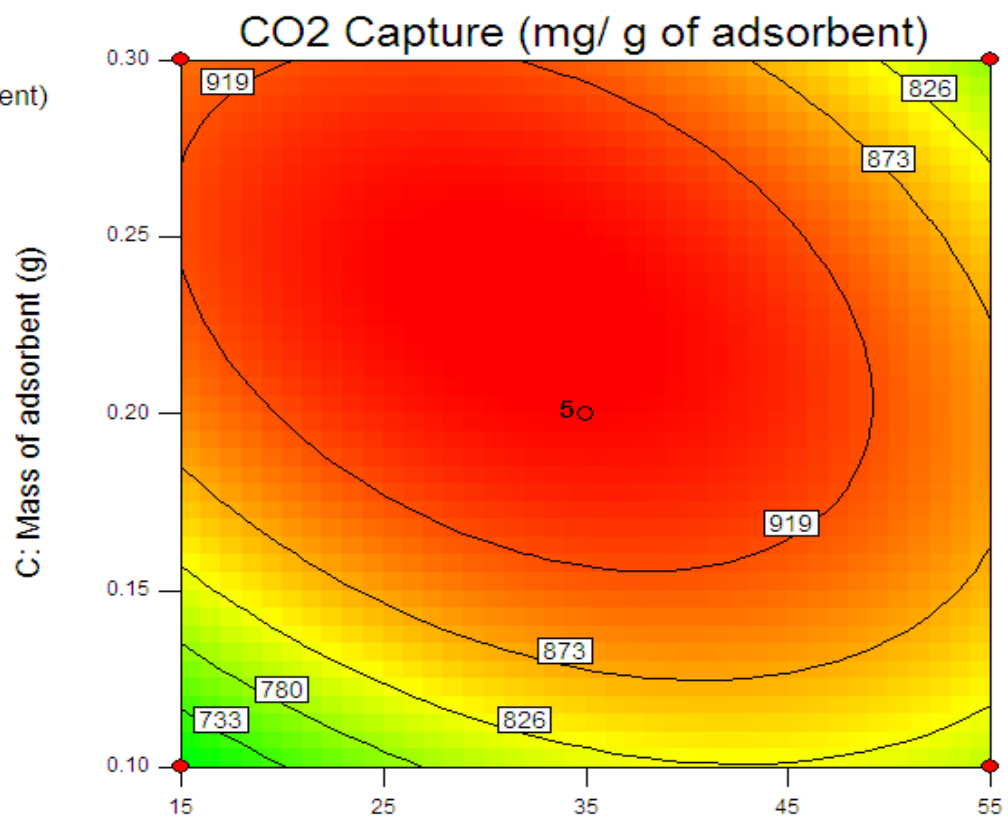

B: Flow rate $(\mathrm{ml} / \mathrm{min})$

Fig. 2 Response surface plots representing the effect of process variables on $\mathrm{CO}_{2}$ capture (A and $\mathrm{B}$ )
Design-Expert $(\circledast)$ Software

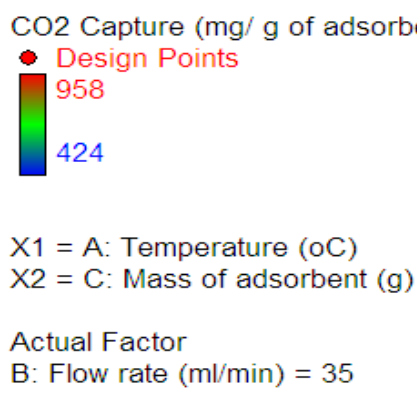

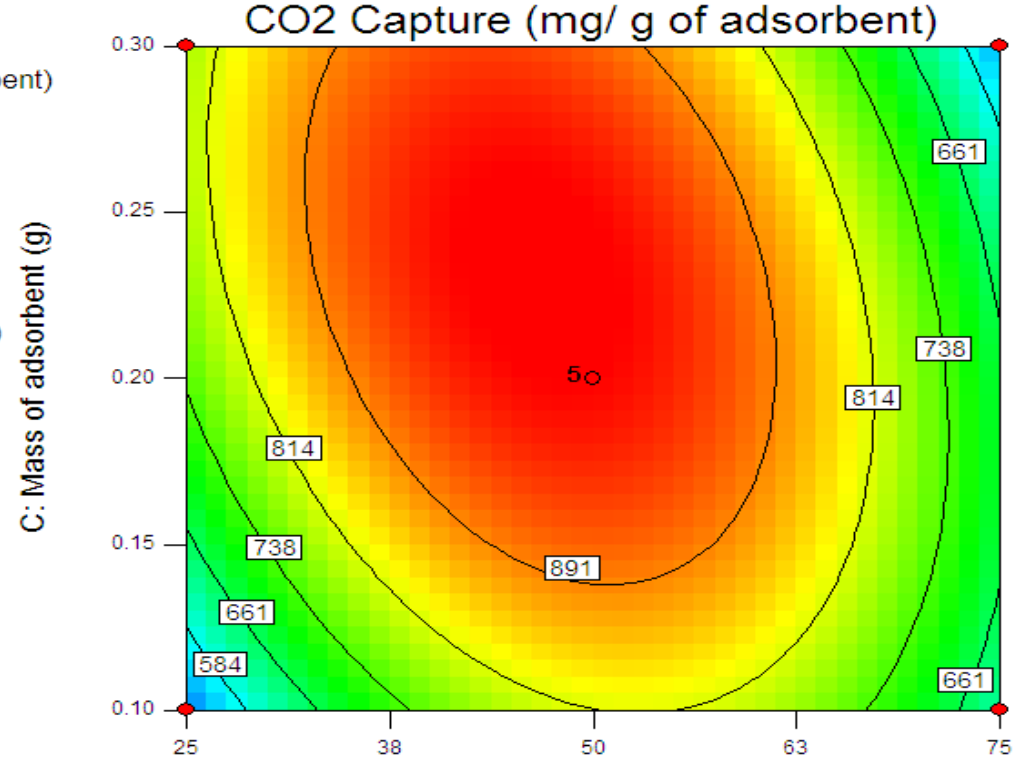

A: Temperature (OC)

Fig. 3 Response surface plots representing the effect of process variables on $\mathrm{CO}_{2}$ capture (A and C)

\section{Statistical Analysis}

$\mathrm{CO}_{2}$ capture in packed bed column is examined by statistical method using RSM. Three factors three levels Box-Behnken response surface design (BBD) is used in order to estimate and optimize the effect of process variables in packed bed column. A total number of 17 experiments were carried out (Table I) and the response is $\mathrm{CO}_{2}$ Capture $\left(\mathrm{R}_{1}: \mathrm{mg} / \mathrm{g}\right.$ of adsorbent). The response values obtained in BBD are analyzed by multi regression analysis
(Table II) in order to select the effective model among various models such as linear, interactive (2FI), quadratic and cubic to explain the $\mathrm{CO}_{2}$ Capture. From the results, it is found that second order polynomial model is found to be best fit with $\mathrm{F}$ value and lower $\mathrm{p}$ value. Therefore the second order polynomial model with linear, interactive and quadratic terms is selected to explain the effects of process variables on $\mathrm{CO}_{2}$ Capture [16]. Final second order polynomial model obtained in terms of coded factors are given below. 
$\mathrm{CO}_{2}$ Capture (mg/g of adsorbent) $=958-36.25 \mathrm{~A}-4.25 \mathrm{~B}+48.50 \mathrm{C}+179 \mathrm{AB}-91.50 \mathrm{AC}-59.50 \mathrm{BC}-250.50 \mathrm{~A}^{2}-71.50 \mathrm{~B}^{2}-96 \mathrm{C}^{2}$

TABLE I STATISTICAL DESIGN OF EXPERIMENTS

\begin{tabular}{|c|c|c|c|c|}
\hline S. No. & A & B & C & R1 \\
\hline 1 & 50 & 35 & 0.2 & 958 \\
\hline 2 & 50 & 35 & 0.2 & 958 \\
\hline 3 & 50 & 35 & 0.2 & 958 \\
\hline 4 & 75 & 35 & 0.1 & 590 \\
\hline 5 & 75 & 15 & 0.2 & 424 \\
\hline 6 & 25 & 35 & 0.3 & 816 \\
\hline 7 & 50 & 55 & 0.3 & 746 \\
\hline 8 & 75 & 35 & 0.3 & 520 \\
\hline 9 & 50 & 15 & 0.1 & 716 \\
\hline 10 & 50 & 35 & 0.2 & 958 \\
\hline 11 & 25 & 35 & 0.1 & 520 \\
\hline 12 & 50 & 35 & 0.2 & 958 \\
\hline 13 & 50 & 15 & 0.3 & 916 \\
\hline 14 & 25 & 15 & 0.2 & 814 \\
\hline 15 & 25 & 55 & 0.2 & 490 \\
\hline 16 & 75 & 55 & 0.2 & 816 \\
\hline 17 & 50 & 55 & 0.1 & 784 \\
\hline
\end{tabular}

Table II Sequential Model Sum Of Square And Model Summary Statistics For Response

\begin{tabular}{|c|c|c|c|c|c|c|c|}
\hline \multirow{2}{*}{ Model } & \multicolumn{7}{|c|}{ Model summary statistics } \\
\hline & Std.Dev. & $\mathbf{R}^{2}$ & Adjusted $\mathrm{R}^{2}$ & Predicted $\mathbf{R}^{2}$ & \multicolumn{2}{|c|}{ Press } & Remarks \\
\hline & \multicolumn{7}{|c|}{$\mathrm{CO}_{2}$ Capture } \\
\hline Linear & 202.4170 & 0.0524 & -0.1662 & -0.6516 & \multicolumn{2}{|c|}{928392.1} & \\
\hline $2 \mathrm{FI}$ & 188.8996 & 0.3652 & -0.0157 & -0.8817 & \multicolumn{2}{|c|}{1057735.5} & \\
\hline Quadratic & 32.5247 & 0.9868 & 0.9699 & 0.7892 & \multicolumn{2}{|c|}{118480.0000} & Suggested \\
\hline Cubic & 0.0000 & 1.0000 & 1.0000 & & \multicolumn{2}{|l|}{+} & Aliased \\
\hline Source & Sum of Squares & Df & Mean Square & F Value & \multicolumn{2}{|c|}{ Prob $>$ F } & Remarks \\
\hline \multicolumn{8}{|c|}{ Sequential model sum of squares for $\mathrm{CO}_{2}$ Capture } \\
\hline Mean & \multicolumn{2}{|c|}{9852668.47} & 1.00 & 9852668.47 & & & \\
\hline Linear & \multicolumn{2}{|c|}{29475.00} & 3.00 & 9825.00 & 0.24 & 0.8670 & \\
\hline 2FI & \multicolumn{2}{|c|}{175814.00} & 3.00 & 58604.67 & 1.64 & 0.2415 & \\
\hline Quadratic & \multicolumn{2}{|c|}{349425.53} & 3.00 & 116475.18 & 110.10 & $<0.0001$ & Suggested \\
\hline Cubic & \multicolumn{2}{|c|}{7405.00} & 3.00 & 2468.33 & 63660000.00 & $<0.0001$ & Aliased \\
\hline
\end{tabular}

Where, A, B and C are temperature, feed flow rate and mass of the adsorbent, respectively. In order to validate the capability of developed second order polynomial model, experimental values are selected randomly from selected process variable ranges and are plotted with model predicted versus actual plots. The data points on this plot lie very close to the diagonal line indicates (Fig. 4) the good adequate agreement between experimental data. Moreover, $P(<0.0001)$ and $F(>1)$ values of response indicates the suitability of developed mathematical models. From these results (Table III), it is concluded that the developed mathematical models can describe the extraction process very robustly. 


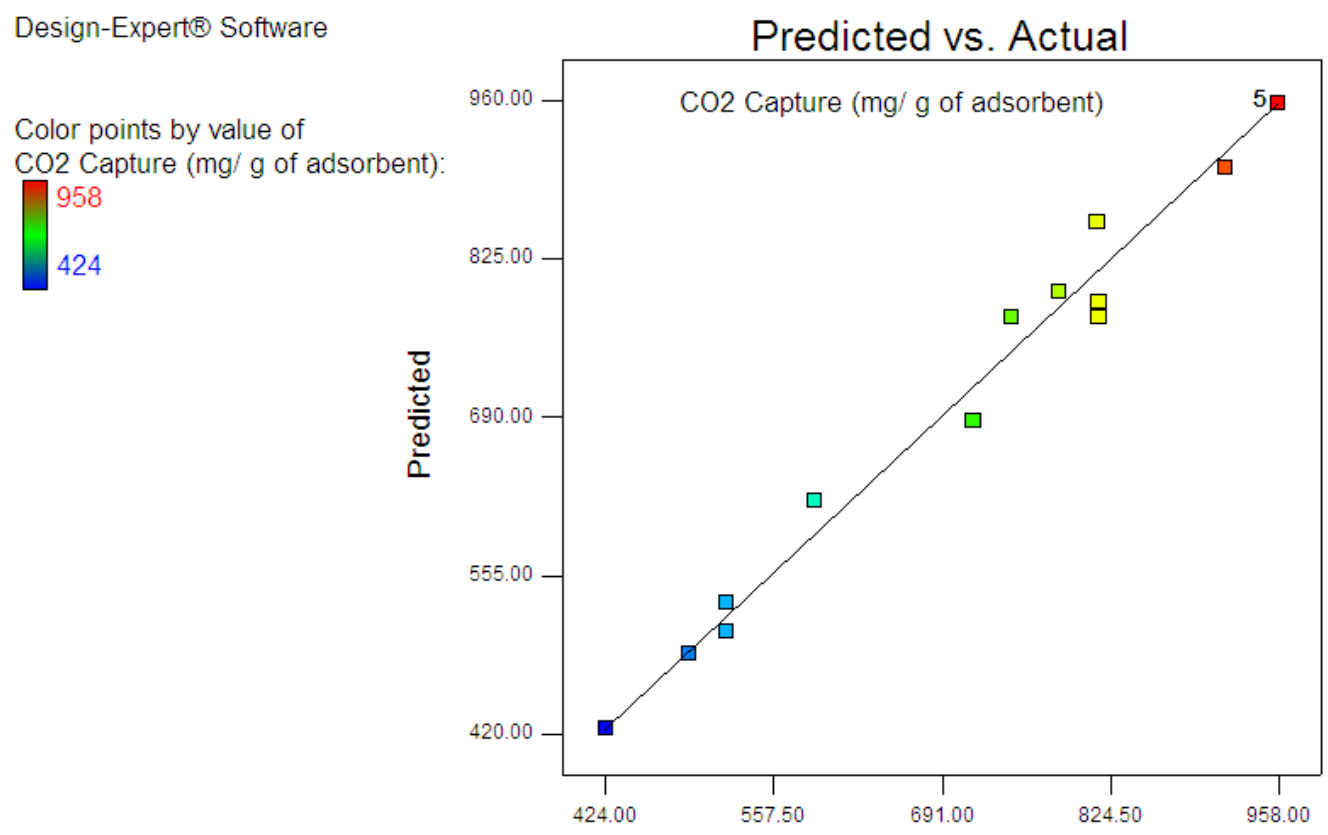

Fig. 4 Perturbation plot for $\mathrm{CO}_{2}$ capture

TABLE IV ANOVA RESUlts FOR $\mathrm{CO}_{2}$ CAPTURE

\begin{tabular}{|l|c|c|c|c|c|l|}
\hline \multicolumn{1}{|c|}{ Source } & $\begin{array}{c}\text { Sum of } \\
\text { Squares }\end{array}$ & df & $\begin{array}{c}\text { Mean } \\
\text { Square }\end{array}$ & $\begin{array}{c}\text { F } \\
\text { Value }\end{array}$ & $\begin{array}{c}\text { p-value } \\
\text { Prob }>\text { F }\end{array}$ & Remarks \\
\hline Model & 554715 & 9 & 61634.9 & 58.264 & $<0.0001$ & significant \\
\hline A-Temperature $\left({ }^{\circ} \mathrm{C}\right)$ & 10512.5 & 1 & 10512.5 & 9.93754 & 0.0161 & \\
\hline B-Flow rate $(\mathrm{ml} / \mathrm{min})$ & 144.5 & 1 & 144.5 & 0.1366 & 0.7226 & \\
\hline C-Mass of adsorbent $(\mathrm{g})$ & 18818 & 1 & 18818 & 17.7888 & 0.0039 & \\
\hline AB & 128164 & 1 & 128164 & 121.154 & $<0.0001$ & \\
\hline AC & 33489 & 1 & 33489 & 31.6574 & 0.0008 & \\
\hline BC & 14161 & 1 & 14161 & 13.3865 & 0.0081 & \\
\hline A2 & 264212 & 1 & 264212 & 249.761 & $<0.0001$ & \\
\hline B2 & 21525.3 & 1 & 21525.3 & 20.348 & 0.0028 & \\
\hline C2 & 38804.2 & 1 & 38804.2 & 36.6819 & 0.0005 & \\
\hline Residual & 7405 & 7 & 1057.86 & & & \\
\hline Lack of Fit & 7405 & 3 & 2468.33 & & & \\
\hline Pure Error & 0 & 4 & 0 & & & \\
\hline Cor Total & 562120 & 16 & & & & \\
\hline
\end{tabular}

\section{E. Optimization and Validation}

In order to determine the optimum operating conditions for $\mathrm{CO}_{2}$ capture in packed bed column, numerical optimization technique is applied. Optimal operating conditions to obtain the maximum electricity from MFC are found to be as follows: temperature of $40^{\circ} \mathrm{C}$, feed flow rate of $30 \mathrm{ml} / \mathrm{min}$ and $0.25 \mathrm{~g}$ of the Poly-(D) glucosamine. Under these optimal conditions, predicted $\mathrm{CO}_{2}$ capture is found to be $956 \mathrm{mg} \mathrm{CO}_{2}$ with desirability value of 0.9854 . The confirmation experiment is carried out in aforementioned conditions and the result obtained is close agreement with predicted one [17-18].

\section{CONCLUSION}

This study focused on $\mathrm{CO}_{2}$ capture in packed bed column reactor using Poly-(D) glucosamine under the various process parameters such as temperature, feed flow rate and mass of the adsorbent. Individual and interactive effective of process parameters on the $\mathrm{CO}_{2}$ capture is examined statistically. The developed second order polynomial model is examined ANOVA and actual versus predicted plot. Numerical optimization is used to optimize the process parameters to capture maximum $\mathrm{CO}_{2}$. The maximum of 956 mg $\mathrm{CO}_{2}$ is captured under the following operating conditions; temperature of $40^{\circ} \mathrm{C}$, feed flow rate of 30 
$\mathrm{ml} / \mathrm{min}$ and $0.25 \mathrm{~g}$ of the Poly-(D) glucosamine. Also, under various conditions experiments were performed in order to verify the reliability of statistical analyses and results were confirmed. Hence, $\mathrm{CO}_{2}$ capture in packed bed column reactor using Poly-(D) glucosamine is a promising method which will helpful to solve the global warming and climate change issues.

\section{REFERENCES}

[1] A. L. Anoar, G. N. Haldera and A. K. Sahab, "Experimental investigation on efficient carbon dioxide capture using piperazine (PZ) activated aqueous methyldiethanolamine (MDEA) solution in a packed column", International Journal of Greenhouse Gas Control., Vol. 64, pp. 163-173, 2017.

[2] C. Chen, J. Kim, D. Park and W. Ahn, "Ethylenediamine grafting on zeolite like metal organic frameworks (ZMOF) for $\mathrm{CO}_{2}$ capture", Materials letters., Vol. 78, pp. 344-347, 2013.

[3] C. Chen, J. Kim, D. Yang, and W. Ahn, "Carbon dioxide adsorption over zeolite-like metal organic frameworks (ZMOFs) having a sodtopology: structure and ion exchange effect", Chemical Engineering Journal., Vol. 168, pp. 1134-1139, 2011.

[4] T. Chitsiga, M. Daramola, N. Wagner and J. Ngoy, "Effect of the presence of water-soluble amines on the carbon dioxide $\left(\mathrm{CO}_{2}\right)$ adsorption capacity of amine-grafted polysuccinimide (PSI) adsorbent during $\mathrm{CO}_{2}$ capture”, Energy Procedia, Vol. 90, pp. 10586, 2016.

[5] W. Haohan, G. Charles, S. Thibault, W. Hao and A. Katie, "Effect of temperature on hydrogen and carbon dioxide adsorption hysteresis in an ultramicroporous MOF", Microporous and Mesoporous Materials, Vol. 5, pp. 186-189, 2016.

[6] A. Imteaz and H. Sung, "Composite of metal organic framework: Preparation and Application in adsorption”, Materials today, Vol. 24, pp. 138-146, 2014.

[7] J. Lin, D. Kang, H. Shan, S. Shi and T. Chung, "A comparison between packed beds and rotating packed beds for $\mathrm{CO}_{2}$ capture using monoethanolamine and dilute aqueous ammonia solutions", International Journal of Greenhouse Gas Control, Vol. 46, pp. 228239, 2016.
[8] W. Lei, J.Wang, Z. Zhang, T. Ziting, S Jiang and L. Chunrong, "Development of Ionic Liquids Tethered to Coconut Shell Activated Carbon for Biogas Upgrading in a Packed Bed”, Energy Technol., Vol. 3, pp. 509-517, 2015.

[9] J. Ma, C. Xin and C. Tan, "Preparation, physicochemical and pharmaceutical characterization of chitosan from Catharsius molossus residue”, International Journal of Biological Macromolecules, Vol. 15, pp. 547-556, 2015.

[10] W. Ningning, Z. Yan, C. Changhong, C. Linyu and D. Hanming, "A $g$ - $\mathrm{C}_{3} \mathrm{~N}_{4}$ supported graphene oxide/ $\mathrm{Ag}_{3} \mathrm{PO}_{4}$ composite with remarkably enhanced photocatalytic activity under visible light", Catalysis Communications, Vol. 15, pp. 68-73, 2015.

[11] J. Prakash Maran, V. Sivakumar, R. Sridhar and K. Thiruganasambandham, "Artificial neural network and response surface methodology modeling in mass transfer parameters predictions during osmotic dehydration of Carcia papaya L", Alexandria Engineering Journal, Vol. 52, pp. 507-516, 2013.

[12] S. Praveen and P. P. Selvi, "Absorption of Carbon dioxide in Packed Column", International Journal of Scientific and Research Publications, Vol. 4, pp. 1-11, 2014.

[13] J. Rowsell and O. Yaghi, Metal-organic frameworks: a new class of porous materials, Microporous and Mesoporous Materials, Vol. 3, pp. 14-22, 2004.

[14] G. Shaohua, L. Pan, Y. Haijun, Z. Yanbei, C.Mingwei, I. Masayoshi, and Z. Haoshen, , "A Layered $\mathrm{P}_{2}$ - and O3-Type Composite as a HighEnergy Cathode for Rechargeable Sodium-Ion Batteries, Ind.Eng.Chem.Res., Vol. 54, pp. 5894 - 5900, 2015.

[15] K. Thirugananasambandham and V. Sivakumar, "Eco-friendly approach of copper (II) ion adsorption on to cotton seed cake and its characterization: Simulation and Validation”, Journal of the Taiwan Institute of Chemical Engineers, Vol. 50, pp. 198-204, 2015.

[16] M. Wang, A. Lawal, P. Stephenson, J. Sidders and C. Ramshaw, "Post-combustion CO2 capture with chemical absorption: A state-ofthe-artreview”, Chemical Engineering Research and Design, Vol. 11, pp. 1609-1624, 2011.

[17] C. Yu, C. Huang and C. Tan, "A Review of $\mathrm{CO}_{2}$ Capture by Absorption and Adsorption”, Taiwan Association for Aerosol Research, Vol. 12, pp. 745-769, 2012.

[18] Q. Yu, D. W. F. Brilman, "Design Strategy for $\mathrm{CO}_{2}$ Adsorption from Ambient Air Using a Supported Amine Based Sorbent in a Fixed Bed Reactor", Energy Procedia, Vol. 11, pp. 6102-6114, 2017. 